\title{
El municipio de Huizúcar: historias, patrimonios e identidades, a través del relato de sus pobladores
}

\author{
José Heriberto Erquicia-Cruz' \\ Martha Marielba Herrera-Reina² \\ Ariana Ninel Pleitez-Quiñónez ${ }^{3}$ \\ Recibido: 12/03/2014 - Aceptado: 12/05/2014
}

\section{Resumen}

En la actualidad, en el territorio salvadoreño existen muchas localidades que poseen un conocimiento parcial o mínimo de sus orígenes, sus historias, sus patrimonios y demás elementos que constituyen y forman parte de sus identidades. La localidad de Huizúcar, ubicada al sur de San Salvador, se ha presentado a través de su historia como uno de los lugares con población de ascendencia indígena de habla nahua-pipil; junto a otros municipios localizados en la misma cordillera. La villa de Huizúcar también es conocida por poseer un templo católico de la época colonial, dedicado a San Miguel Arcángel, el cual es una obra arquitectónica colonial de gran valor patrimonial. Los elementos patrimoniales de la cultura material y las manifestaciones de la cultura viva de sus habitantes son componentes esenciales en la construcción de la historia de las poblaciones de El Salvador.

\section{Palabras clave}

Huizúcar, historia, patrimonio, identidades, religiosidad popular

\section{Abstract}

Within the Salvadoran territory, there are currently many locations with minimal or partial knowledge of their origins, their stories, and their heritage, as well as other elements that constitute and are part of their identities. The area of Huizúcar, located south of San Salvador, has been presented throughout its history as one of the places with a nahua-pipil speaking population of indigenous descent, along with other municipalities located in the same range. The villa of Huizúcar is also known for its Colonial period Catholic church dedicated to St. Michael the Archangel, which is a colonial architectural work of great historical value. The heritage assets of material culture and the expressions of a living culture in all its inhabitants are essential components in the construction of the history of the people of $\mathrm{El}$ Salvador.

\section{Keywords}

Huizúcar, history, heritage, identities, popular religiosity.

José Heriberto Erquicia Cruz es licenciado en Arqueología, maestro en Docencia Universitaria, maestro en Ciencias Sociales y actualmente estudiante de doctorado en Historia. Investigador de la Universidad Tecnológica de El Salvador. jose.erquicia@utec.edu.sv

2 Martha Marielba Herrera Reina es licenciada en Antropología, co-investigadora en la Universidad Tecnológica de El Salvador. marielba@gmail.com

3 Ariana Ninel Pleitez Quiñónez es licenciada en Antropología, co-investigadora en la Universidad Tecnológica de El Salvador. ninelantro@gmail.com 


\section{Introducción}

En el actual territorio salvadoreño existen diversas localidades que poseen un conocimiento parcial 0 mínimo de sus orígenes, sus historias, sus patrimonios y demás elementos que constituyen y forman parte de sus identidades. La localidad de Huizúcar, ubicada al sur de San Salvador, se ha presentado a través de su historia como uno de los lugares con población de ascendencia indígena de habla nahua-pipil; junto a otros municipios localizados en la misma cordillera. La villa de Huizúcar, también es conocida por poseer un templo católico de la época colonial, dedicado a San Miguel Arcángel, el cual es una obra arquitectónica colonial de gran valor patrimonial.

Los elementos patrimoniales de la cultura material y las manifestaciones de la cultura viva de sus habitantes, son componentes esenciales en la construcción de la historia de las poblaciones de El Salvador. La enseñanza de la historia en el sistema educativo salvadoreño tiene grandes vacíos, uno de tantos, es no tomar en cuenta las historias locales, dedicándose únicamente a examinar una historia nacional y urbana con muchos sesgos, excluyendo a las comunidades que se encuentran al margen de la sociedad salvadoreña dominante.

Es por ello importante que la comunidad del municipio de Huizúcar, desde la agencia de sus pobladores, exprese cuál es su historia, cómo la entienden, qué elementos y prácticas consideran que son parte de su patrimonio cultural.

Es fundamental la visibilización de la comunidad de Huizúcar, pues aunque se encuentre próxima a la ciudad de San Salvador, esta villa pasa desapercibida por diversas razones. Descubrir, mostrar, conocer, analizar e interpretar las historias locales, las tradiciones y las diversas prácticas culturales que se desarrollan entre los individuos de los cantones que componen el municipio, a partir de la viva voz de los actores sociales, como agentes de cambio, era una de las razones vitales de la propuesta de investigación.

Consta, en cada una de las comunidades de El Salvador, una pretensión por conocer y valorar su historia, de la que muchas veces se tienen ideas fragmentadas. Un pueblo que comprende, valora y se apropia de la historia de su comunidad se convierte en un colectivo que emprende de mejor manera las vicisitudes a que se enfrenta día con día.
El objetivo elemental de la investigación recaía en elaborar una etnografía del municipio de Huizúcar, documentando y registrando los lugares y sitios patrimoniales, que desde las comunidades guardan y mantienen un vínculo estrecho entre sus pobladores, a fin de comprender la manera en que los pobladores de Huizúcar construyen sus identidades locales a partir del reconocimiento de distintos eventos de la historia y el patrimonio de su municipio.

Esta investigación se realizó a través de un convenio específico de cooperación entre la Universidad Tecnológica de El Salvador, Utec, y la Asociación Comunitaria Unida por el Agua y la Agricultura, Acua, instituciones interesadas en establecer vínculos, por el reconocimiento e importancia de promover el rescate cultural de la cordillera del Bálsamo, en la cual se ubica Huizúcar.

\section{Metodología}

En el abordaje metodológico se utilizó el método etnográfico, que permitió conocer la información de primera mano de los pobladores del municipio de Huizúcar, tanto en el área urbana como en la rural, a partir de entrevistas semiestructuradas focalizadas, desarrolladas en un entorno de confianza en el que los entrevistados alcanzaran profundizar con sus respuestas a las preguntas que se les plantearon; todo ello con miras a obtener más información. Por medio de esta técnica, se construyó un instrumento donde se abordaron los tópicos de interés en la búsqueda de respuestas del problema de investigación (Vela Peón, 2001).

Asimismo, se utilizó la técnica de grupos focales. Las entrevistas logradas mediante la estrategia tenían como propósito el registrar cómo los participantes elaboran grupalmente su realidad y experiencia. Esta técnica está asociada a la idea de grupos de discusión organizados alrededor de una temática, dentro de la cual se delimitan metodológicamente el objeto y los objetivos de los grupos focales en la contribución que hacen al conocimiento de lo social (Aigneren, 2002, pp. 2-3).

Se manejó también el método historiográfico heurístico con la búsqueda y recopilación de fuentes documentales primarias y secundarias, para luego realizar un análisis y una crítica de dichas fuentes. De igual manera, se recurrió al método hermenéutico como parte importante de la 
lectura, comprensión e interpretación de las fuentes obtenidas a partir de su búsqueda y recopilación. Teniendo en cuenta la complejidad que debe tener un trabajo acerca de historia, identidad y patrimonio local, se delimitó el desarrollo de resultados a partir de los ejes de religiosidad popular, historia y patrimonio; desarrollando así algunas de las herramientas teóricas que permitieron analizar este contexto sociocultural.

Para el presente estudio se desarrolló un total de 15 entrevistas a informantes de Huizúcar, tanto en el área urbana como en la rural. Asimismo, se llevaron a cabo 10 grupos focales, tres urbanos y los restantes en el área rural. Uno en el barrio El Centro y dos en el barrio El Calvario; así: en los cantones Nazaret, Ojos de Agua, San Juan Buena Vista y La Lima; y en los caseríos Santa Marta y La Esperanza.

\section{Resultados de la investigación}

En cuanto a la cuestión patrimonial, Huizúcar es un lugar rico en dichos recursos, incluso es identificado por gente de otros municipios y por ellos mismos como un lugar "antiguo" y "cultural". De la variedad de elementos culturales que la comunidad identifica como propios, los principales son: el templo colonial, las expresiones religiosas, la rica tradición oral, el oficio de las mujeres vendedoras y la religiosidad popular.

El templo colonial San Miguel Arcángel es uno de los rasgos patrimoniales más sobresalientes de Huizúcar, es representativo para la comunidad católica; y al mismo tiempo es un recurso significativo para los proyectos de turismo. La majestuosidad de la iglesia está con los nueve retablos barrocos que hay en su interior; están hechos de madera tallada y originalmente estuvieron recubiertos por "pan de oro", 1 material que fue usado para dar la tonalidad dorada.
En El Salvador colonial, la construcción de templos tuvo que afrontar diversos obstáculos, como la falta de materiales fáciles de modelar y los pocos artesanos, por tanto, la virtud de la arquitectura de las iglesias coloniales es el uso inteligente de materiales exiguos y su hábil combinación (Yánez, 1970). He aquí un punto importante, puesto que las iglesias erigidas en el período colonial en El Salvador nunca fueron una copia exacta de las construidas en Europa, sino que son adaptaciones de acuerdo con las condiciones socioculturales y económicas. Con ello, se está hablando de recepción activa de elementos culturales. Así, la construcción de una edificación tan grande, en un lugar estratégico por su altura, con sus altares, imaginería y pinturas, son rasgos que llevan a pensar que este lugar estaba dentro de un territorio económicamente importante.

La fecha de construcción de la iglesia no está bien definida, ya que en su fachada se encuentra grabado el año de 1785 , $y$, sin embargo, la primera fecha que aparece en el libro de bautizos es de 1781. Según un informe de restauración, en un documento encontrado en el Archivo General de Centro América (AGCA) aparece una nota acerca de la "reedificación del templo parroquial, San Miguel de Guizúcar", en 1740 (Dirección General de Patrimonio, 1974). Por lo tanto, es probable que la iglesia funcionara a principios del siglo XVIII, pero la construcción, o más bien la "reedificación", para ser fiel al término usado en la fuente, comienza en 1740. Cuarenta y cinco años más tarde, en 1785, el templo es finalizado.

El templo católico ha sufrido diversas modificaciones; y la que en la actualidad se observa no es exactamente la misma que hace más de doscientos años. Es en este sentido importante saber, ¿qué papel juega la comunidad en la conservación de un monumento de este tipo? Para responder la interrogante, hace falta hablar de algunos de los cambios que ha tenido la iglesia.

1 Láminas muy delgadas y finas de oro para recubrir retablos e imágenes. 
Tabla 1

Trabajos de conservación y restauración del templo colonial de San Miguel Arcángel Huizúcar a través del tiempo

\begin{tabular}{ll} 
Año & Detalle de actividades \\
\hline 1740 & Reedificación \\
1891 & Reconstrucción de los estribos de la iglesia por "temblor" \\
1896 & Reparación de varios bloques de la iglesia \\
1898 & Repellos por dentro, por fuera y pared norte \\
1900 & Reconstrucción de la sacristía \\
1902 & Reparación del techo \\
1903 & Apertura de una puerta al costado sur \\
1920 & Cambio total del envarillado por madera en el tejado \\
1930 & Levantaron torre frente a la puerta mayor de la iglesia "por ser el lugar más a \\
& propósito por su altura para que la carátula fuera vita por la mayoría del vecindario"
\end{tabular}

FUENTE: Cuadro elaborado con la información del Archivo General de la Nación, Dirección General de Patrimonio 1974.

En 1930, el presidente de la República de El Salvador, Pío Romero Bosque donó una torre, y por medio de una junta la comunidad decidió que lo mejor era colocarla frente a la iglesia, por ser el lugar más alto, desde el cual todo el vecindario podría apreciarla. Para llevar a cabo la construcción se consultó antes a la curia de San Salvador, instancia que al parecer accedió a la obra². Para terminar la construcción de la torre, que adornó la fachada, se contó además con las aportaciones de Alejandro Mixco y de Eduardo Guirola. ${ }^{3}$ Dos años más tarde hubo un temporal, de 1934, que ocasionó tres derrumbes en la iglesia, en la parte sur y en el frente, el convento también sufrió daños. Debido a los daños, en 1935 se organizó una junta constructora para trabajar en la reparación de la iglesia; solo los más ancianos recuerdan este suceso. La junta estaba conformada por personas del pueblo. Había un interés de la comunidad por velar constantemente para las reparaciones, por lo tanto, se ve reflejada en la actual iglesia que su historia va más allá de su construcción colonial; es el trabajo de los pobladores que en diferentes momentos se han interesado por mantener el templo.

Hacia 1974, Patrimonio Cultural Ilega a Huizúcar porque la iglesia se encontraba en estado de total ruina. El deterioro era "avanzado en todas sus partes", puesto que tenía termitas en los elementos de madera, la humedad y las plagas habían dañado el edificio; el techo también estaba en malas condiciones, pues había una colonia de murciélagos viviendo en el entretecho. Tanto el techo como las paredes estaban muy afectados por la humedad, de modo que en junio de 1974 comenzaron los trabajos por la restauración a través de la Administración del Patrimonio Cultural de la Dirección de Sitios y Monumentos Históricos. Las actividades de restauración se dieron en tres etapas debido a problemas con el financiamiento, se trabajó cinco meses durante 1974, seis meses en 1975 y cinco durante 1976. Un dato interesante es que en el informe de restauración se dice que la fachada principal estaba obstruida totalmente por un pórtico y una torre de reciente construcción, había perdido la armonía estilística del conjunto monumental:

La torre colocada sobre el contrafuerte esquinero izquierdo lo destruía parcialmente por haber sido levantado para servir de campanario, sobre una base de mampostería y con un cuerpo de madera forrada de lámina. El pórtico estaba superpuesto en el centro de la fachada, sobre el acceso principal de la iglesia, ocultando gran parte de los rasgos arquitectónicos de este edificio (Archivo General de la Nación, Dirección General de Patrimonio, 1974).

Según uno de los informantes, lo que ocurrió es que la torre se había caído. Entonces conformaron una junta para recaudar el dinero y velar por su reconstrucción; cuando ellos habían levantado las bases, la Dirección de Patrimonio Cultural intervino e hizo que botaran lo que ya tenían reconstruido.

Con la reconstrucción, lo que se desea —según los parámetros universales de patrimonio- es restaurar el

2 Libro de gobierno de la Parroquia San Miguel Arcángel, Tomo II

3 Libro de gobierno de la Parroquia San Miguel Arcángel, Tomo II 
monumento en su totalidad, quitando cualquier agregado reciente. Aunque para la comunidad esta torre era importante, probablemente porque reflejaba el trabajo de ellos, lo primero que hizo la institución estatal fue retirar la estructura de la fachada, que para ellos "no tenía ningún valor" y obstruía la fachada. Luego se siguió con las paredes y el techo, al cual se le cambiaron las tejas que estaban en malas condiciones y procuraron dejar las que estaban en buen estado. Al finalizar dichas intervenciones, exactamente el 25 de julio de 1978, la iglesia se declaró formalmente monumento nacional. La Asamblea Legislativa lo reconoció como patrimonio por medio de la publicación en el Diario Oficial como sigue:

Las iglesias con los nombres de Huizúcar, ubicada en la población del mismo nombre, departamento de La Libertad; del Barrio de Roma, ubicación en Ciudad Barrios, departamento de San Miguel; de Candelaria, ubicada en el Barrio Candelaria, de la ciudad de San Salvador, departamento del mismo nombre y las ruinas de la iglesia de Tacuba, ubicados en la Villa de Tacuba, departamento de Ahuachapán, son exponentes de una evolución arquitectónica y pertenecen a etapas culturales de la historia colonial de suma importancia para nuestro país; ya que en ellas se encuentran los rasgos de las construcciones y del arte producidos por nuestros antepasados ya influenciados por las ideas europeas de esa época por lo que su valor artístico e histórico es excepcional ( Archivo General de la Nación, Ministerio del Interior del S. G. de la República del Salvador 1868 "Decreto para erigir pueblo en Huizúcar". San Salvador).

Como puede verse, el Estado salvadoreño reconoce que el valor de la iglesia es por lo artístico y lo histórico. La conformación de juntas para velar por la reconstrucción de la iglesia, en 1935 y la anterior a 1974, son ejemplos de cómo las personas de la localidad se organizan para garantizar la conservación del templo colonial. El aspecto de la organización de la comunidad es un agente clave para la conservación del patrimonio cultural local.

En enero y febrero de 2001, el territorio salvadoreño se vio afectado por dos sismos que destruyeron muchos edificios patrimoniales a escala nacional; uno de ellos fue el templo colonial de San Miguel Arcángel Huizúcar. El estado del inmueble era bastante crítico: el techo, cielo, estructura, elementos y ornamentos se encontraban en mal estado (Registro de Bienes Muebles, 2004).

Aún así, la gente estuvo desde el primer momento pendiente de lo que ocurría con la iglesia; se conformó un comité pro Calvario, que ayudó a la terminación de la construcción de una iglesia pequeña en el barrio El Calvario. Esta había sido iniciada por un sacerdote anterior en 1989 , y en este momento fue usada para que viviera allí el padre y para continuar con las actividades parroquiales, que en ningún momento fueron suspendidas. Incluso en el 2003, dos años después del terremoto, las fiestas patronales, uno de los eventos más importantes para la comunidad, fueron realizadas con bastante afluencia.

Entonces surgió la duda: ¿qué harían con el templo? Una de las personas entrevistadas explica:

Bueno, la gente se fue a preguntar si se iba a botar o se iba a construir o qué iba a pasar por los daños que había sufrido, ya que los altares estaban despedazados y ya no tenían remedio. Entonces él (el padre Cristóbal) consultó con Concultura ${ }^{4}$ qué era lo que se tenía que hacer; y ya le proponían que botarla y volverla a construir, porque sentían que el costo era demasiado para poder restaurarla.

La comunidad asegura que Concultura les decía que lo mejor era que la iglesia quedara como una ruina, incluso cuando una joven preocupada por el estado de la iglesia preguntó directamente a los especialistas de la institución cultural si era cierto que no la podían volver a abrir, le dijeron: "Mire, si usted quiere ver esta iglesia otra vez y entrar a una misa, usted no lo va a poder hacer, tal vez sus hijos o sus nietos, porque ya no. Lo mejor es botarla y hacer una nueva". Sin embargo, la gente no quería una iglesia nueva, de modo que la comunidad jugó un papel determinante en decidir lo que se haría con la iglesia. Así lo expresaban los habitantes:

Ha sido trabajo de nosotros y de algunos donativos, pero más que todo de la comunidad. Cuando la iglesia se cayó, el padre dijo que la iban a botar, pero nosotros le dijimos que no. En algún momento pensamos que no podríamos volver a abrirla, porque quedó todo el muro del fondo destruido y los retablos botados en el suelo. La iglesia El Calvario no

4 Consejo Nacional para la Cultura y el Arte. 
es lo mismo, porque está construida con otro tipo de ladrillos [ladrillos de barro cocido] no es lo mismo que la iglesia más grande.

En la administración del alcalde Ricardo Montes Chávez, en 2003, el consejo municipal propuso la posibilidad de contribuir para la restauración. Según explicó Montes Chávez, por tratarse de una iglesia que ha sido declarada patrimonio de la nación, se permite que se invierta parte de los fondos que otorga el Estado en ella. En otras circunstancias los gastos corresponderían únicamente a la Iglesia. Este es un punto de conflicto con respecto al gobierno central, como lo menciona una persona que estuvo en la alcaldía en este periodo:

Todavía somos cuestionados. La corte de cuentas está cuestionado eso porque se le ayudó a la iglesia y por ser patrimonio cultural; $y$ viendo la necesidad es que se decidió ayudar, y porque la gente lo pidió; también notas y firmas. La gente pidió eso. Pero fue cuestionado, aun cuando ya íbamos a terminar, como que se limitó la ayuda porque habíamos sido cuestionados. Pero la gente siguió ayudando con ventas, con rifas y cosas así para reconstruir los altares, las paredes, todo, para pintar.

Una vez se tomó la decisión de levantar la iglesia, la gente se fue organizando en diferentes actividades, como lo menciona un entrevistado:

Cuando el padre nos dio la noticia de que ya no se iba a botar, se iba a reconstruir, nos organizamos como comunidad por sectores, por grupos, en horarios; allí todo el día estaba abierto para llegar a ayudar: a sacar el ripio, a levantar los altares, todo lo hizo la comunidad, el trabajo de la comunidad. Cuando ya se logró levantar todo, se comenzó a ver qué se hacía, a ver cuál era el costo para restauración del altar; se tuvo la ayuda del alcalde, el doctor Montes Chávez, en ese momento. Allí fue donde él empezó. Luego, lo demás poco a poco se fue haciendo con la comunidad: los arreglos del techo, la limpieza del piso. Eso fue bastante, y aún hasta ahora no se ha terminado, ya que hay bastante daño por la teja, del ripio. Así poco a poco ha ido caminando la restauración; porque alrededor de $\$ 6.000$ ha andado el costo de cada uno para poderlo restaurar; el altar mayor.
Sumado al trabajo que se realizaba durante el día, por la noche los hombres hacían turnos para cuidar la iglesia, sobre todo porque los materiales quedaban allí y tenían que ver que no entrara nadie a llevarse las cosas. Uno de los señores que hacían guardia expresaba: "La cosa era aportar sin esperar algo a cambio". Como puede verse, el "dar desinteresadamente" es resaltado en esta etapa de reconstrucción y es un valor que se mantiene.

La mano de obra era una parte de lo que se tenía que hacer en aquel momento. Se sabía que los costos de la obra eran elevados, así que la gente se organizó para conseguir dinero con una serie de actividades: se levantó un cine parroquial, se organizaron cenas, excursiones, baratillos, torneos de fútbol y turnos, lo cual hacía más intensas las actividades parroquiales, al mismo tiempo que daba cohesión a la comunidad católica. Los sacerdotes que estuvieron durante ese periodo en Huizúcar admiraron que la gente conseguía dinero "a puras ventas de pastelitos". Por ello, la gente entrevistada dice que la mayor parte del esfuerzo fue de la comunidad, ya que ellos fueron los que de una forma u otra buscaron la manera de conseguir los fondos y realizar el trabajo. Así lo relataba un entrevistado:

De ahí que toda la población ayudó de una u otra manera. Se hacían turnos, excursiones, todo lo que te podas imaginar para recaudar fondos; una buena directiva que llevaba ese control de los recursos económicos, buena contabilidad de los ingresos y de los egresos. Hasta que se hizo lo del convento; ya no se hizo lo del campanario porque lo original no lo llevaba.

Durante el período de reconstrucción, al ver que las cosas iban caminando, la gente se entusiasmó, y en un momento determinado un grupo de personas de Huizúcar que viven en los Estados Unidos de América y en Italia se pusieron de acuerdo para enviar un donativo importante para la reconstrucción, lo cual reivindica el valor de la iglesia como elemento identitario; y esa acción trascendía las fronteras nacionales. La gente que ha tenido que migrar, de alguna forma sigue trabajando por el pueblo y sintiéndose parte de él.

Al mismo tiempo, el sacerdote gestionó donaciones de dinero y materiales de construcción, como madera y cemento. Aunque se continuaba trabajando por la restauración de los altares, en el 2007 lograron abrir las puertas de la 
iglesia. Hasta la fecha, la gente sigue trabajando por su mantenimiento. Los grupos parroquiales se encargan de la limpieza; se pinta el edificio una vez al año y se organizan turnos para recaudar fondos para mejorarla.

Uno de los proyectos que ha ayudado a solventar esta parte económica son las noches turísticas, que consisten en que una vez al mes llevan varios buses con turistas de San Salvador, para que conozcan el pueblo. Esta noche la gente en Huizúcar se prepara con una fiesta para recibir a los visitantes; realizan ventas, puntos artísticos, quema de pólvora y una exposición de objetos coloniales y de interés cultural.

En este evento ha ido incrementándose la participación de la gente de la comunidad como guías turísticas, narrando la historia de la iglesia, además de hablar de sus materiales y medidas. Los guías hablan del orgullo que representa haber reconstruido la iglesia en tan poco tiempo y de cómo esta es parte del patrimonio de su pueblo. Ese orgullo hace que la identidad con respecto a Huizúcar se refuerce, tal y como lo dijeron en las entrevistas dos señoras, hablando acerca de qué significa para ellas ser de Huizúcar:

Lo primero es la iglesia colonial, porque cuando uno va de visita a otro lado lo primero es conocer la casa de Dios. Ya cuando uno ha ido a la casa de Dios, puede ir a otro lado a divertirse y ver las demás cosas que hay. Para mí, ser de aquí de Huizúcar significa ser devota a San Miguelito, estar pendiente de la iglesia.

Por su parte, en las fiestas populares el atractivo principal de las noches turísticas es la iglesia. Pero, además del edificio en sí, la Iglesia es una comunidad de creyentes que viven y practican una serie de actividades religiosas que unifican y al mismo tiempo caracterizan a la comunidad. Muestra de ello es el volante que entrega la Iglesia durante las noches turísticas para recibir a los invitados, que dice lo siguiente:

\section{Con una población de 12 mil habitantes, Huizúcar constituye uno de los poblados que conserva sus tradiciones culturales, religión, y vive fervientemente de muchas de las historias que cuentan: cómo se originó esta ciudad y la formación católica, heredada de los tiempos de la Colonia.}

Los huizucareños se consideran como un pueblo que tiene muy arraigada a su vida las creencias religiosas. Hay orden en las fiestas, orden en las procesiones. Probablemente es la forma en que la religión oficial intenta marcar su predominio, la aceptación de la comunidad católica de la solemnidad, de lo sagrado de la religión. Un entrevistado nos comenta: "En Semana Santa habían escoltas, que eran los que se encargaban de ver que se hicieran las cosas como debía de ser".

En el transcurso del 2011 al 2013, una de las investigadoras de este trabajo tuvo la oportunidad de asistir a varias de las actividades religiosas, desde las más grandes, como la Semana Santa y las fiestas patronales en honor a San miguel Arcángel, hasta las más pequeñas, como el Día de la Cruz o los rezos del Sagrado Corazón. En cada una de ellas se observaba un orden, una solemnidad y un respeto hacia cada una de las actividades por parte de los feligreses. En las procesiones se respetan las dos columnas atrás de las imágenes de los santos. En Viernes Santo, los primeros en pasar sobre las alfombras son los que llevan a Jesucristo; aun así, mucha gente considera que estas devociones se están perdiendo.

Lo que ha sucedido es que las fiestas han tenido diversos cambios. Por ejemplo, el Desfile de las Palmas, que se hace en mayo, y es celebrado también en Panchimalco, en los Planes de Renderos y en Rosario de Mora, territorios aledaños. Consiste en que cada uno de los sectores de la Iglesia se reúne en una casa para ensartar las flores en palmas; las palmas se hacen de diferentes colores, formas y tamaños. Por la tarde hay una procesión en la que llevan a la Virgen en medio de las palmas; la procesión es precedida por el grupo de historiantes que bailan durante todo el recorrido. Pues, comentan los entrevistados que antes esta procesión se daba todos los días de mayo, pero poco a poco participaba menos gente, de modo que lo cambiaron y ahora se hace la festividad un solo día domingo. En esta celebración también existe una dinámica de dar y de colaborar combinada con elementos tradicionales que ahora se ocupan como elementos turísticos. En los últimos dos años este evento ha atraído a muchos turistas de San Salvador.

La procesión de las Palmas fue transformada para adaptarse a las condiciones sociales de la gente, pero hay otras fiestas que dejaron de celebrarse, como la fiesta de Las Ánimas, que se celebraba el 1 de noviembre. Uno de los entrevistados, que era niño cuando se daban estas celebraciones, cuenta que la fiesta de las Ánimas consistía en correr de cantón en cantón pidiendo fruta, como caña de azúcar o ayote en miel; 
había unos señores que precedían la procesión y tocaban el pito y el tambor. Según dice otro informante de mayor edad, esto se acabó mientras estaba allí el padre Héctor, porque ese tipo de cosas no aportaban en nada a la iglesia. La gente aprovechaba para emborracharse, por lo que se consideraba una celebración pagana que llamaba al desorden. Por su parte, un señor originario de cantón Nazaret, de Huizúcar, comenta:

Salían unos jóvenes con unas campanitas que van sonando. Dicen que la costumbre era pedir, pero ellos no, llegaban a la casa a desmantelar. Si había caña o palos de naranja se metían a cortar. Lo que hallaban se llevaban, por eso la gente se preocupaba por cortar antes las cosas.

En comparación con la procesión de las Palmas, la del día de las Ánimas desaparece. Desde el punto de vista del patrimonio, unos elementos desaparecen y otros se conservan, de acuerdo con lo que la comunidad misma considere digno de conservar. Ambas eran celebraciones religiosas populares, pero solo la que tenía los símbolos de la religión oficial más explícitos es la que se queda, lo cual indica, en este caso, el apego de la comunidad a la Iglesia oficial.

Entonces es lo tradicional lo que se intenta resaltar con el turismo; y esto en ocasiones festivas adquiere un nuevo matiz, ya que no todo lo tradicional se mantiene. Algunos elementos culturales relacionados con lo indígena connotan significado negativo y por eso se evitan. He aquí la ruta de paso entre lo tradicional y lo moderno, un filtro que selecciona los elementos que se apegan a los valores vigentes.

La devoción a San Miguel Arcángel es más evidente durante las fiestas patronales en septiembre. El pueblo se llena de visitantes, incluso muchos de los huizucareños que residen en Estados Unidos de América regresan en estas fechas para celebrar dichas actividades. Las fiestas completas duran dos semanas, desde el 15 de septiembre, con las celebraciones por la independencia, se inaugura el festejo previo al 28 de septiembre, día de San Miguel Arcángel. A partir de ese día, todas las mañanas se turnan las instituciones de la comunidad para llevar a cabo las alboradas. Estas procesiones inician alrededor de las 4:30 de la mañana, cuando un grupo de gente enciende unas bolas de fuego, una banda de música acompaña y recorren las calles del casco urbano. Al terminar la vuelta cantan las mañanitas a San Miguel Arcángel y se reúnen en un punto específico para repartir el atol shuco ${ }^{5}$ con pan.

Uno de los miembros de Adescovi (Asociación de Desarrollo Comunal Visión) decía que, para él, las alboradas son características de Huizúcar porque siempre se han hecho en las fiestas; y además en las observaciones de campo se notó que la música es algo importante en Huizúcar, ya que hay muchos que se dedican a ella o tocan algún instrumento como pasatiempo.

En el transcurso de esas dos semanas cada institución desarrolla actividades el día que le corresponde; hacen las elecciones de la reina, desfiles, fiestas o ventas. Por su parte, la Iglesia católica celebra una misa por la tarde con un padre invitado, que normalmente es originario de Huizúcar o ha estado a cargo de la parroquia. A pesar de la lluvia o de los días de turismo, cada una de las actividades se lleva a cabo con normalidad.

Los eventos se intensifican el 28 de septiembre, cuando se reciben las entradas. Es el día de mayor trabajo para la cofradía porque deben atender a los grupos que llegan a dejar las entradas. Estas las llegan a dejar diferentes grupos de la Iglesia, ya sean de jóvenes, de niños, de los cantones o personas de otros municipios. Días antes de las fiestas se acostumbra visitar a personas que por años dan dinero para las fiestas; se las visita para preguntarles si en este año se contará con su colaboración. La cofradía trabaja en ello casi todo el año, de manera que es un grupo bastante activo. Muchos de los que pertenecen a la cofradía han estado ahí por años, y, además, sus padres fueron parte del mismo grupo. No obstante, este año se ha incorporado gente joven al grupo.

Posterior a la misa se saca la carroza de san Miguel Arcángel, se hace una procesión que sale de la iglesia, se descubre al patrono y se recorre el casco urbano. Al regresar se hace la quema de toritos pintos. ${ }^{6}$

\footnotetext{
5 Es una bebida caliente, la cual está compuesta de masa de maíz fermentado, agua, sal, y alguashte. Además se le agregan frijoles negros enteros con caldo y una pizca de sal. Se sirve en un depósito hecho del fruto de un árbol llamado "morro" que sirve a manera de recipiente.

6 La danza del Torito Pinto es una pantomima con baile y canto que lleva fuegos artificiales, imitando o interpretando a su manera una corrida de toros española.
} 
Suele suceder que las actividades de la iglesia compiten con las de la alcaldía que al mismo tiempo organiza una celebración o un evento en el parque central, ante ello un miembro de la comunidad católica dice: "la fiesta está bien, pero antes de eso hay que acudir a las cosas de Dios", los grupos parroquiales llaman la atención de lo importante que es la fiesta del pueblo, pero antes de ir a las celebraciones que se hacen frente a la alcaldía, es necesario asistir a la iglesia. Por ello expresan que, "la alegría [material] está en las fiestas, pero hay que ver también la parte espiritual, refriéndose a la colaboración con la iglesia, deben llevarse a cabo las dos cosas a la par."

El día 29 de septiembre la celebración culmina más o menos al medio día, cuando el Arzobispo celebra la misa y procede a las confirmaciones, luego hay un almuerzo al que se invita a las personas e instituciones que han colaborado con el desarrollo de las fiestas patronales.

Ahora bien, las actividades de la cofradía van más allá de las fiestas patronales. Otra de las funciones importantes de la cofradía es que, cuando uno de los miembros está enfermo o ha dejado de llegar a la iglesia, se le hace una visita. De esta manera colaboran con la cohesión de la comunidad católica. En Huizúcar las cofradías en la actualidad únicamente son dos: la del Niño Dios, que prepara las posadas en diciembre; y la más fuerte es la de san Miguel Arcángel, que, según el coordinador de este grupo, existe desde que se fundó la iglesia; el se encarga de recoger y administrar las entradas, es decir, el dinero que se ocupará para financiar las fiestas patronales. En los cantones, las cofradías organizaban bailes para recaudar fondos, para las entradas en las fiestas patronales de Huizúcar centro. El día de San Miguel Arcángel se hacía un largo recorrido para entregar esta colaboración. Así lo expresa un entrevistado:

Cuando eran las fiestas de Huizúcar, había un grupo que iba allá a dejar la entrada. Allá iba la gente de noche con lámparas, porque está lejos; hay que atravesarse [el catón] La Lima. Se pasa el río de Huiza para llegar al pueblo, y en invierno grandes lodazales; $y$ antes eran las calles empedradas. Para eso, durante el año, cada cierto tiempo, hacían fiestas de parte de la capitana para traer fondos que le iban a entregar a Huizúcar.

Si se trata de colaborar con la Iglesia, la gente está muy pendiente. Aunque no dispongan del tiempo para ir a las actividades, siempre entregan su colaboración a tiempo. Lo que está presente en la dinámica de la religión es que el dar es un deber. Cuando se pide alguna ayuda para Ia Iglesia, nadie lo cuestiona, simplemente es algo que se debe de hacer. Cabe destacar que este valor se encuentra presente no solo en las prácticas religiosas, sino además en la vida cotidiana, como lo expresa el siguiente entrevistado:

Con mi mamá, si ella tiene algo, pues ella lo comparte; y no importa si ella se queda sin nada. $Y$ yo lo viví bastante eso en la época en la que estudié, porque yo vivía a la par de la escuela de bachillerato; $y$ a la hora de comer ella me pasaba comida, y no solo para mí. Ella me decía: "Dale a tus compañeros hasta donde alcance". Si ya no le alcanzaba la comida, me pasaba fruta; algún guineo, para los que no alcanzaba.

En los grupos focales se observó que los valores religiosos son valores culturales de Huizúcar. Así, las cofradías juegan un papel muy importante, ya que se preocupan por la cohesión de los grupos y, de hecho, su coordinador debe ser una persona de confianza y que se involucra en las actividades de la comunidad. En una de las entrevistas con una señora mayor, de Huizúcar, explicó las diferencias de las cofradías anteriores con la actual:

Ya no se celebra en las casas, donde se daba chicha y aguardiente. Ahora se da en la iglesia, y se da fresco de canela y pan picado. Antes se daba la fiesta, y había una parte pagana. El que entra a la cofradía no es del momento, sino que tienen muchas actividades; $y$ alli tienen que estar.

Entonces, con respecto a esta diferencia entre cofradías parroquiales, se preguntó cómo era mejor. A lo cual la gente de la cofradía respondió que es mejor ahora, porque antes se generaba desorden cuando llegaba algún borracho y no lo podían sacar de su casa. En cambio, en la iglesia no pasa lo mismo. Allí no llega ningún borracho y, por tanto, se mantiene el orden. Anteriormente existía la cofradía de la Virgen de Guadalupe, de Santa María Magdalena, El Carmen y Las Animas. Así los comentaba una persona consultada al respecto:

También está la fiesta de María Magdalena, porque en esa época había la cofradía; en esa época la gente se interesaba para hacer la cofradía, y 
hasta la fecha así es. Pero algunas cosas se han desaparecido; por ejemplo, esa de María Magdalena; otra es la del Carmen. La gente colaboraba. La fiesta del Señor de la Caridad. Hoy, como ya perdimos la fe. Antes montón de ventas que ponía la gente en la noche y se quemaban los toritos. Antes en la fiesta del Señor de la Caridad celebrábamos; y hoy tenemos esa inquietud. Parece que esas cosas están desapareciendo, y nosotros quisiéramos que no desaparezcan.

Hay muchas opiniones de las personas con respecto al cambio cultural. Una de ellas expresaba: "Todas esas tradiciones no son de ahorita. Porque bien que aquí que no a todos los padres les gusta. Hubo uno al que no le gustaba". Aunque el padre opinara diferente, la comunidad sigue teniendo el control de las actividades que realizan, al igual que de la reconstrucción. Si la gente se opone, tienen el poder de decidir sobre estos elementos particulares. La religión dicta una serie de patrones, pero es la religión popular y sus dinámicas las que expresan las particularidades de la localidad. En ningún lugar está escrito que los historiantes bailen durante las fiestas patronales, pero este tipo de elementos apropiados hacen que la comunidad exprese su identidad y valores culturales.

Otra cara de la religiosidad popular en Huizúcar se ubica dentro de los grupos poblacionales de origen pipil asentados en la cordillera del Bálsamo, ${ }^{7}$ por lo que probablemente se pueda identificar a esta región geográfica como un espacio de reproducción cultural. La cultura material prehispánica ha legado a la zona dos lugares con manifestaciones gráficorupestres que tienen, entre otros elementos, motivos de Tláloc (deidad de la lluvia y el agua). El primero de ellos es EI Letrero del Diablo en el municipio de Jicalapa y, el segundo, El Letrero ubicado en el municipio de Chiltiupán. Cada uno de ellos se ubica cerca de afluentes de agua como por ejemplo los ríos. En el petrograbado de representación de la deidad Tláloc (sitio El Letrero), probablemente sus pobladores realizaron rituales donde se lo veneraba para pedir por el agua (Escamilla y Fowler, 2013, p. 162).

Esta petición de agua se puede identificar en la diversidad de fiestas religiosas cristianas que se realizan en Huizúcar, que podrían tener un posible origen prehispánico, y que actualmente se relacionan con la lluvia, el agua y la agricultura. El ciclo agrícola juega un papel fundamental en las creencias religiosas actuales. Así, se adapta el ciclo agrícola con los rituales y las estaciones climáticas; por ejemplo, en enero es el tiempo para el agradecimiento de los dones recibidos y la bendición de la nueva semilla (fiestas de la Sagrada Familia y el Niño Dios); en febrero da inicio la preparación de la semilla y el ciclo agrícola (fiesta de Candelaria); en marzo y abril es la época de la siembra en los campos o cerros; aparecen en algunos lugares las primeras lluvias (fiestas de San José y Semana Santa). En los meses de mayo a octubre es el tiempo de los santos patronos, para el control del temporal. Entonces, la petición de la lluvia y la fertilidad comienza con la fiesta de la Santa Cruz (3 de mayo); julio es propicio para el desarrollo y crecimiento de la milpa; se ritualiza con la fiesta de santa María Magdalena (22 de julio); entre agosto y septiembre hay un período que se presenta como el momento de la primicia, donde los elotes crecen y se madura la mazorca, concluyendo con la cosecha de elotes en septiembre. Es en este mes que se lleva a cabo una de las festividades más importantes en honor al santo patrono san Miguel Arcángel, este asociado al ciclo agrícola, al que se le celebra y pide por el agua para propiciar buenas cosechas. Este patrono se ubica en el punto más alto del sector urbano. Retomando el análisis de Jarquín (2010), son especialmente las montañas las que fungieron como residencia de algunos dioses e incluso fueron consideradas como entes sagrados. Cada una personificaba la figura específica de un dios, como el caso particular de Tláloc (el agua), entre los nahuas, quien representaba la deidad de la fertilidad agrícola, cuya residencia era el Tlalocan, al interior de las montañas. Tierra, agua, flores y frutos, paisaje y ambiente hacían un conjunto digno de su dueño, que en su mansión, en su paraíso, no manejaba el rayo cegador ni el trueno espantoso, sino solo mostraba su aspecto amable, dando al lugar sensaciones de bienestar, regocijo y paz. Este espacio rechazó estados de cansancio y preocupaciones, cesó el dolor y la tristeza (Jarquín, 2010, p. 68).

El sincretismo religioso de san Miguelito, como le llaman los huizucareños, ofrece la particularidad de retomar a la deidad prehispánica de Tláloc, que, en este caso, se vuelve el señor de las lluvias, la milpa y la buena cosecha. Existe un punto en el que el arcángel y Tláloc llegan a ser uno mismo. Según Villela (2009), en sus análisis de las deidades de la Iluvia, se refiere a san Miguel Arcángel como el que

7 Esta zona geográfica y cultural se conforma de los municipios de Teotepeque, Jicalapa, Chiltiupán, Tamanique, Comasagua, La Libertad, Santa Tecla, Zaragoza, San José Villanueva, Huizúcar y Nuevo Cuscatlán. 
comanda —en el final de la temporada agrícolaa los trabajadores, a los 'ángelus', quienes se han encargado de verter el preciado líquido desde las nubes, donde tienen sus cántaros que contienen el agua de lluvia. Es por ello que, en rituales de aseguramiento de la cosecha, en su día, se le implora para que ya no caiga más lluvia, para que se termine el temporal y ordene a los ángelus que dejen de trabajar (Villeda, 2009, p. 71).

Para estas fechas, la fiesta de la maduración del elote y sus primicias se celebraban en el mes Ochpaniztli (31 de agosto-19 de septiembre), que se trataba del nacimiento del dios del maíz, que aun pertenecía al ciclo de la estación de lluvias (Broda, 2009). Si se toma en cuenta que, según el calendario pipil actual, en El Salvador, tiene un mes de diferencia en relación con el calendario propuesto por Broda, entonces, esta festividad local se conmemora entre el 27 de septiembre-16 de octubre, por lo que también se celebra la caída de los frutos en Huizúcar con la festividad a san Miguel Arcángel.

Leer los contextos histórico, geográfico, cultural y agrícola puede ser un elemento que narre una realidad en concreto. Para este caso, la comunidad agrícola de Huizúcar, que le ha dado personalidad y particularidad a una imagen sagrada, un mito, una historia; al final, una apropiación del icono cultural religioso que representa el arcángel. Poder acceder a este icono de la agricultura, implica a los pedidores de las buenas lluvias y las cosechas, buscarlo y llegar hasta su lugar de "residencia". En el último día de la celebración, deben subir literalmente al cerro, lugar donde habita, es decir, el mundo de las nubes y las lluvias, para luego descender al mundo y compartir con los huizucareños de las festividades en su honor como uno más de la procesión, como un humano más en el mundo. Con el paso del tiempo, muchas comunidades encontraron mecanismos de supervivencia de su cosmovisión y cosmogonía en la que comparten y reproducen mitos y ritos que le dan sentido al orden que ellos mismos han establecido en su entorno, y que se han adaptado al contexto donde va a reproducirse, a lo mejor cargado de nuevos significados; nuevos discursos que en su esencia no pierden la cultura mesoamericana su pertenencia.

Un patrimonio más de Huizúcar son sus mujeres vendedoras y comerciantes. Como se ha explicado anteriormente, el municipio de Huizúcar es bastante amplio en su territorio rural en comparación con su zona urbana, por lo tanto, en la actualidad cuenta con una diversidad de recursos naturales, ríos, quebradas, montañas y demás paisajes. Las personas entrevistadas de mayor edad comentaron que, básicamente, la actividad a la que se han dedicado todo el tiempo es la agricultura y el trabajo en las fincas. Esta última actividad fue modificada después de la reforma agraria. Aún así Huizúcar siempre ha tenido bastantes espacios que producen frutas y hortalizas, que las personas cosechan y venden en diversos mercados de la región. Un relato de una mujer lo expresaba así: "Había mucha pobreza; así que la gente se dedicaba a vender en San Salvador. Por ejemplo, se vendían ramos en día Domingo de Ramos; allí estaba yo cuando enterraron a monseñor Romero" - recuerda.

Ante la situación de precariedad de la comunidad de Huizúcar, y para aportar a la economía familiar, muchas mujeres recolectan la fruta que se produce en las fincas y terrenos aledaños y la comercian en los mercados y calles de San Salvador. Es una actividad que se ha hecho desde hace mucho tiempo, aún mientras el pueblo no contaba con accesos pavimentados ni transporte colectivo, como sucede ahora. Así lo expresaba una entrevistada:

Salíamos a las 5 [de la mañana de Huizúcar] y llegábamos a las 9 [a San Salvador]. La primera vez que yo fui a pie, iba con mi mamá, con una canastada de jocotes en la cabeza. Yo, la nuca, al siguiente día, no la podía mover de hinchada, y los pies también. Yo ya no me levanté; que, mire, amanecí gateando. Yo iba con mi papá a vender leña a San Salvador. Allá, todavía las calles eran unas calles viejas; y después empezaron a ir dos buses. Eran dos, no más; y la gente, como sentía muy caro el transporte, lo que hacían era irse en la mañana en picop; $y$, después, regresarse caminando.

Además, este trabajo es común en los cantones. Las mujeres venden en el lugar que se encuentre más cercano, ya sea San Salvador, Santa Tecla, San José Villanueva o el puerto de La Libertad, con lo cual ellas abastecen los mercados de esos lugares, y al mismo tiempo son el sostén de sus hogares.

Mi mamá me decía: "Mañana voy a Santa Tecla, recogé los huevos". Uno ya sabía dónde estaban los huevos, y en un ratito recogía una canastada 
de huevos. Los chiles que habían allí por la casa los vendía ella; granadilla, esa de hueso. Nosotros vivíamos en una lomita y habían macollas. íbamos a la quebrada a cortar las granadillas; y ella se venía al cantón con las granadillas, los huevos, los chiles. Y ya en la tarde llevaba comida para ocho días.

Incluso en el período del conflicto armado de la década de 1980, las mujeres salían adelante con esta ocupación para sostener la economía familiar. Así comenta una señora:

Fue una etapa bien complicada. Mi mamá me cuenta. Es que ella nos crió de la agricultura del pueblo; que acá lo principal es la venta de frutas y verduras, porque en la época que nos tuvo abundaba la piña; en las matas se maduraban los guineos. $Y$ parte de eso se ha venido perdiendo en parte por el mismo cambio climático que se ha venido dando.

A pesar de que las frutas ya no sean tan abundantes, hay muchas mujeres que compran en el mercado y las revenden en algunas residenciales de San Salvador. Esta forma de "rebuscarse" por salir adelante es motivo de orgullo para muchas mujeres huizucareñas. Fue un punto en común de las entrevistas que dijeran que alguien se dedica a vender fruta, o que algunos de los hombres opinaran: "Así es como mi mamá nos sacó adelante". Por esta razón se justifica que las mujeres vendedoras son parte del patrimonio económico de Huizúcar.

El cambio cultural muchas veces es producido por decisiones y situaciones de poder, mientras que otras es producido por factores sociales relacionados con lo económico. En el caso de las mujeres vendedoras, algunas personas de los cantones que se dedican a la agricultura expresaron que se sienten que viven aisladas porque compran a un precio, pero cuando quieren vender sus productos les bajan los precios, de modo que no alcanzan a sacar los costos. Teniendo en cuenta que el patrimonio cultural heredado es resultado y expresión de un proceso histórico (Batalla, 1993), y, por tanto, el proceso patrimonial hace referencia al pasado, cada uno de los elementos culturales descritos: la iglesia colonial, la religión popular, las historias orales y las mujeres vendedoras son elementos muy distintos que se han desarrollado tradicionalmente en Huizúcar y se han modificado de acuerdo con las necesidades actuales, de modo que se verifica que el patrimonio es un proceso de producción y circulación.
Al mismo tiempo, hay que considerar que el patrimonio son aquellos elementos "de los que echa mano para enfrentar sus problemas [...] para formular e intentar sus aspiraciones y sus proyectos; para imaginar gozar y expresarse" (Batalla, 1997, p. 38). De esta manera, el patrimonio permite a la comunidad que lo posee proyectarse al futuro, siendo esta una de las características más profundas del tema patrimonial. A partir de este se construye la esencia de la comunidad. Sea tangible o intangible, el patrimonio siempre está ligado a condiciones socioculturales, y además tiene un significado y valor para la comunidad que muchas veces es diferente a lo que esperan instancias nacionales o internacionales que trabajan el tema, profundizando así las relaciones de exclusiones económica y cultural.

La parte manifiesta de estos rasgos culturales suele ser modificada rápidamente. Sin embargo, la parte más profunda donde se encuentran los valores se mantiene, o se modifica levemente. Puede apreciarse cómo, en los elementos descritos, se mantiene el valor de "dar desinteresadamente y sin esperar nada a cambio". Así se mantiene, al mismo tiempo, la cohesión de los grupos que conforman la comunidad.

\section{Consideraciones finales}

El municipio de Huizúcar, al sur de San Salvador, guarda dentro de su territorio y entre cada uno de sus pobladores un enorme capital de tradiciones, relatos y memorias, que conforman una diversidad de historias, patrimonios e identidades. Su cultura material se enriquece con las narraciones sobre sus ancestros indígenas y hallazgos casuales de material prehispánico; su legado colonial es visto a través del templo consagrado a san Miguel Arcángel; que dentro de las paredes del santuario resguarda un patrimonio de imaginería y otros artefactos de interés para la herencia local y nacional. Pero el patrimonio del lugar debe verse ligado a una gran riqueza, que se entiende a través de la tradición oral, las danzas, los bailes y demás expresiones religiosas y civiles que son manifestadas por las personas de Huizúcar.

El patrimonio es la forma en que la comunidad expresa su identidad, conservando aquellos elementos culturales que se apegan a las nuevas necesidades socioculturales. En el caso de Huizúcar, la iglesia ha sido campo de confrontación de intereses de diversos grupos sociales. Al inicio la iglesia era una imposición del régimen colonial; y aunque 
posteriormente la religión católica es un rasgo apropiado por la comunidad, las decisiones en cuanto a la iglesia siguen siendo un punto de discusión entre grupos sociales.

Con la iglesia se da pauta a otra cara del patrimonio: la religión, que también es interpretación local de patrimonio, ya que la forma en que la comunidad se muestra devota hacia las tradiciones religiosas es particular del lugar. La devoción a san Miguel Arcángel se renueva constantemente con los relatos de las apariciones, que mantienen viva la creencia y lo sagrado que san Miguel representa. Por otra parte, existen relatos mágicos que son reproducidos en la comunidad. En ellos se expresa el valor de lo antiguo y al mismo tiempo se establece que los valores del catolicismo son especialmente importantes en el pueblo.

La cuestión étnica es un eje transversal de esta investigación, pues se percibe en cada una de las expresiones de la comunidad huizucareña. Con ello se quiso consultar, desde el instrumento de las entrevistas y grupos focales, con el interrogante siguiente: "¿Hay indígenas en Huizúcar?". En la mayor parte de las respuestas se dijo que no. Luego, entrando en un entorno más de confianza, empezaron a surgir las referencias a lo indígena, ancestros que hablaban nahuat, fenotipos indígenas, arquitectura de las casas de habitación, utilización de espacios, oralidad, conocimientos sobre la agricultura, prácticas culinarias, en fin, una gama de elementos asociados a la cosmovisión indígena.

Huizúcar es uno de los 63 municipios del territorio salvadoreño que muestran población indígena (Mined, 2003, p. 34). Sin embargo, para el Censo Nacional de Población de 2007, menos del $1 \%$ de su población se reconoció como indígena. Casi un siglo antes, en 1912, los datos de las actas de bautizo y de defunción de la población del municipio de Huizúcar mostraban que entre el 75 y $80 \%$ del total de la población documentada en el municipio era indígena. El proyecto del mestizaje, civilizatorio y modernizante, concebido desde el Estado y las elites salvadoreñas, fue progresando a pasos agigantados en la concepción del ser indígena en Huizúcar, pues solamente ocho años después, en 1920, la población adscrita como indígena pasó a ser el $50 \%$, frente a $11 \%$ de ladinos y $39 \%$ descritos como "salvadoreños", según los registros de defunción analizados en esta investigación.

El proceso histórico de la religiosidad popular huizucareña presenta elementos que identifican a su comunidad. Estos son una mezcla de pensamiento indígena campesino con acontecimientos históricos que han permitido la fusión de estos para establecer una forma concreta de entender el mundo en el que conviven vivos, muertos, espíritus, santos y deidades. Estos, a su vez, han normado a la sociedad donde aparecen y se desarrollan dentro del plano humano (social, moral, económico) y dentro del espiritual, ya sea a través de la magia y/o la religión.

El mundo campesino, como en otros lugares, está inmerso dentro de la mitología agrícola mesoamericana y su mundo mágico. Para esto habría que replantearse qué es ser mesoamericano en el siglo XXI y analizar, qué es un nahual de esta época, y a partir de ahí comprender, desde nuevas posturas, la complejidad de las sociedades actuales, esto porque muchas veces se siguen retomando elementos de ambos conceptos que ya no son del todo aplicables en la actualidad. En estos nuevos procesos, la memoria colectiva juega un papel determinante porque ese pasado social define identidades que arrastran y proyectan lo que ha de venir, lo que dará continuidad al pensamiento campesino religioso indígena de los huizucareños en un contexto delimitado por el tiempo y el espacio, generando una larga cadena de sincretismos y de replanteamientos de elementos simbólicos que tienen un sentido especial para quienes los reproducen.

\section{Referencias bibliográficas}

Aigneren, M. (2002) "La técnica de recolección de información mendiante los grupos focales". En: Revista La Sociología en sus escenarios, No.6, Centro de Estudios de Opinión, Universidad de Antioquia, Colombia.

Batalla, G. (1997) "Nuestro patrimonio cultural, un laberinto de significados" En: Enrique Florescano, compilador, "El Patrimonio Nacional de México", Fondo de Cultura Económica, México D. F.

Broda, J (2009). "Las fiestas del posclásico a los dioses de la lluvia". En Revista Arqueología Mexicana. Dioses de la lluvia. Marzo-abril. Vol. XVI. Núm. 96. p.p 58-63. México.

Escamilla, M. y Fowler, W (2013). "Proyecto migraciones nahua-pipiles del postclásico en la cordillera del Bálsamo". Recopilación investigativa 2012. Tomo II. Universidad Tecnológica de El Salvador. 1. ${ }^{\text {a Edición. }}$ San Salvador, El Salvador.

Jarquín, M. (2010). "La festividad de san Miguel Arcángel". 
En: $X$ Coloquio internacional sobre Otopames. Instituto nacional de lenguas indígenas, Universidad Nacional Autónoma de México. México.

Ministerio de Educación, Concultura, Pueblos indígenas, Banco Mundial, RUTA. (2003). Perfil de los pueblos indígenas de El Salvador. San Salvador, El Salvador.

Vela Peón, F. (2001). "Un acto metodológico básico de la investigación social: la entrevista cualitativa". En: María Luisa Tarrés, "Observar, escuchar y comprender sobre la tradición cualitativa en la investigación social", p. 63-95, Flacso y el Colegio de México, México, 2001.

Villela, S (2009). "El culto a las deidades de la lluvia en la Montaña de Guerrero". En Revista Arqueología Mexicana. Dioses de la lluvia. Marzo-abril. Vol. XVI. Núm. 96, pp. 69-72. México.

Yánez, G. (1970) Iglesias coloniales en El Salvador. Editorial Universitaria, San Salvador, El Salvador.

\section{Fuentes de archivos}

AGN, Archivo General de la Nación. Dirección General de Patrimonio (1974). "Informe general sobre la restauración de la iglesia en Huizúcar".

AGN, Archivo General de la Nación. Ministerio del Interior del S. G. de la República del Salvador, 1868. "Decreto para erigir pueblo en Huizúcar". San Salvador.

Dirección Nacional de Patrimonio Cultural, Coordinación de Zonas y documentos históricos (2004). "Ficha de registro de la iglesia San Miguel Arcángel en Huizúcar". Libros de Gobierno de la Parroquia San Miguel Arcángel, Tomos I, II y III.

\section{Figura 1}

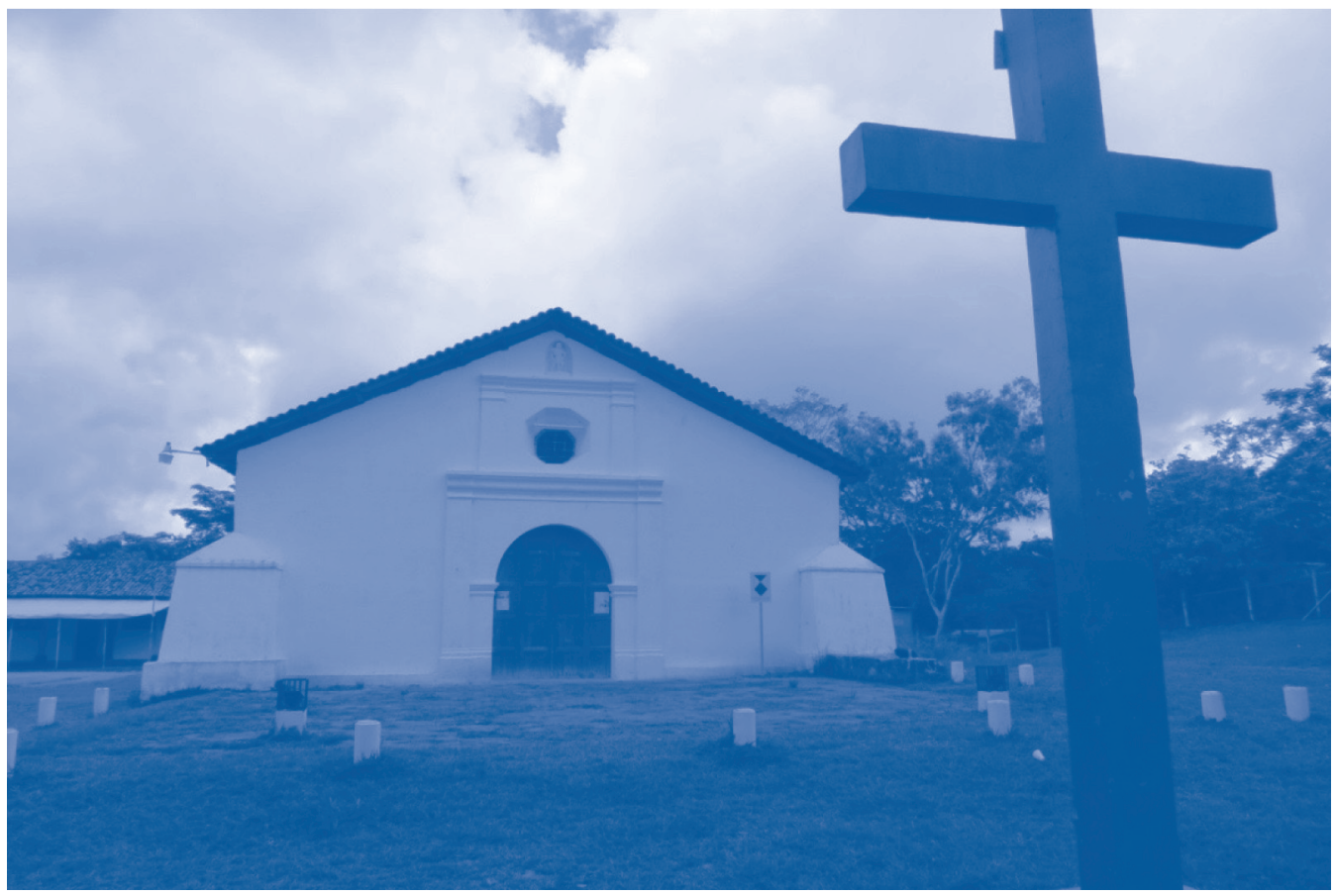

Vista de la fachada del templo colonial de san Miguel Arcángel de Huizúcar. Fotografía: Heriberto Erquicia, para esta investigación. 
Figura 2

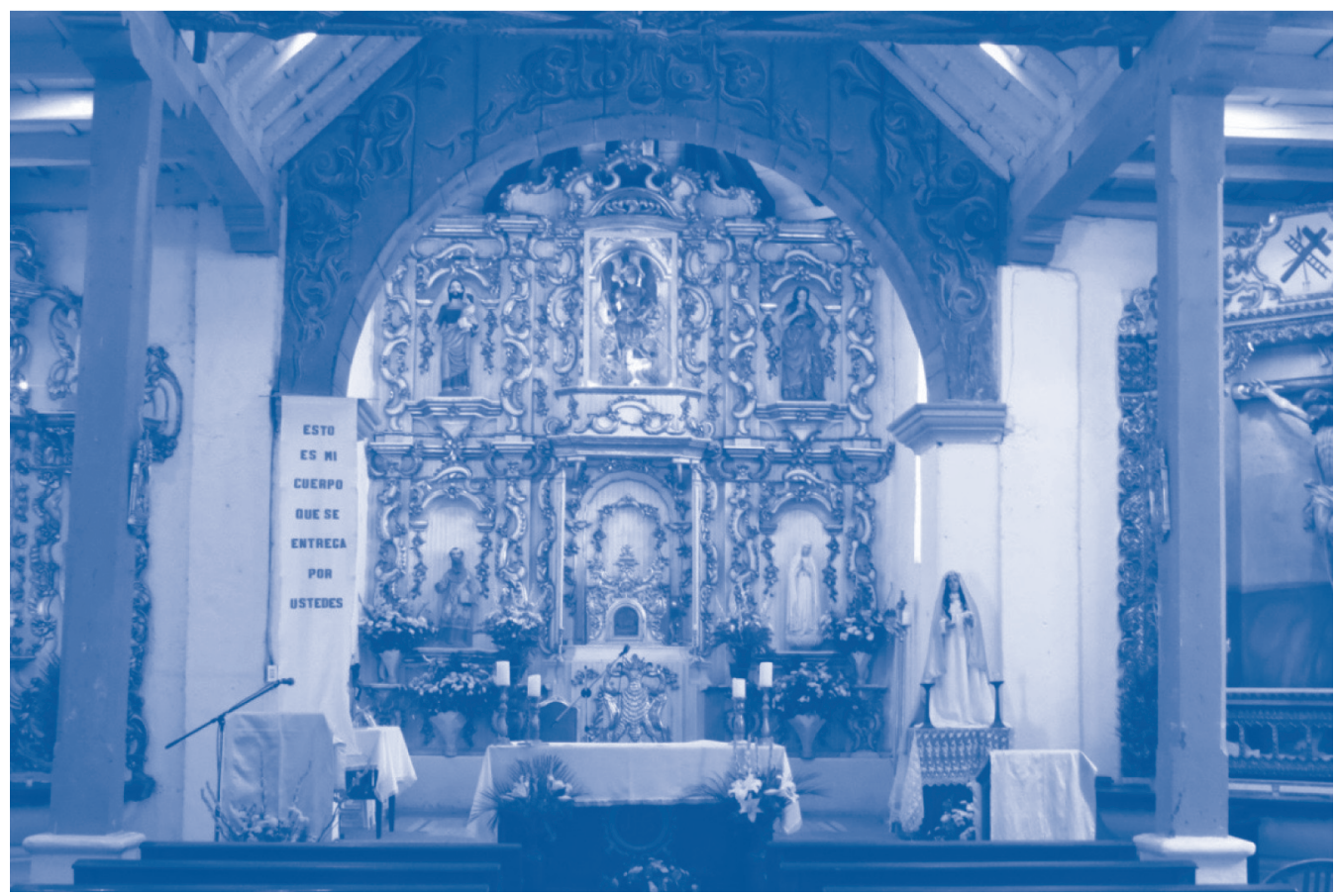

Retablo del altar mayor del templo colonial de san Miguel Arcángel de Huizúcar. Fotografía: Heriberto Erquicia, para esta investigación.

Figura 3

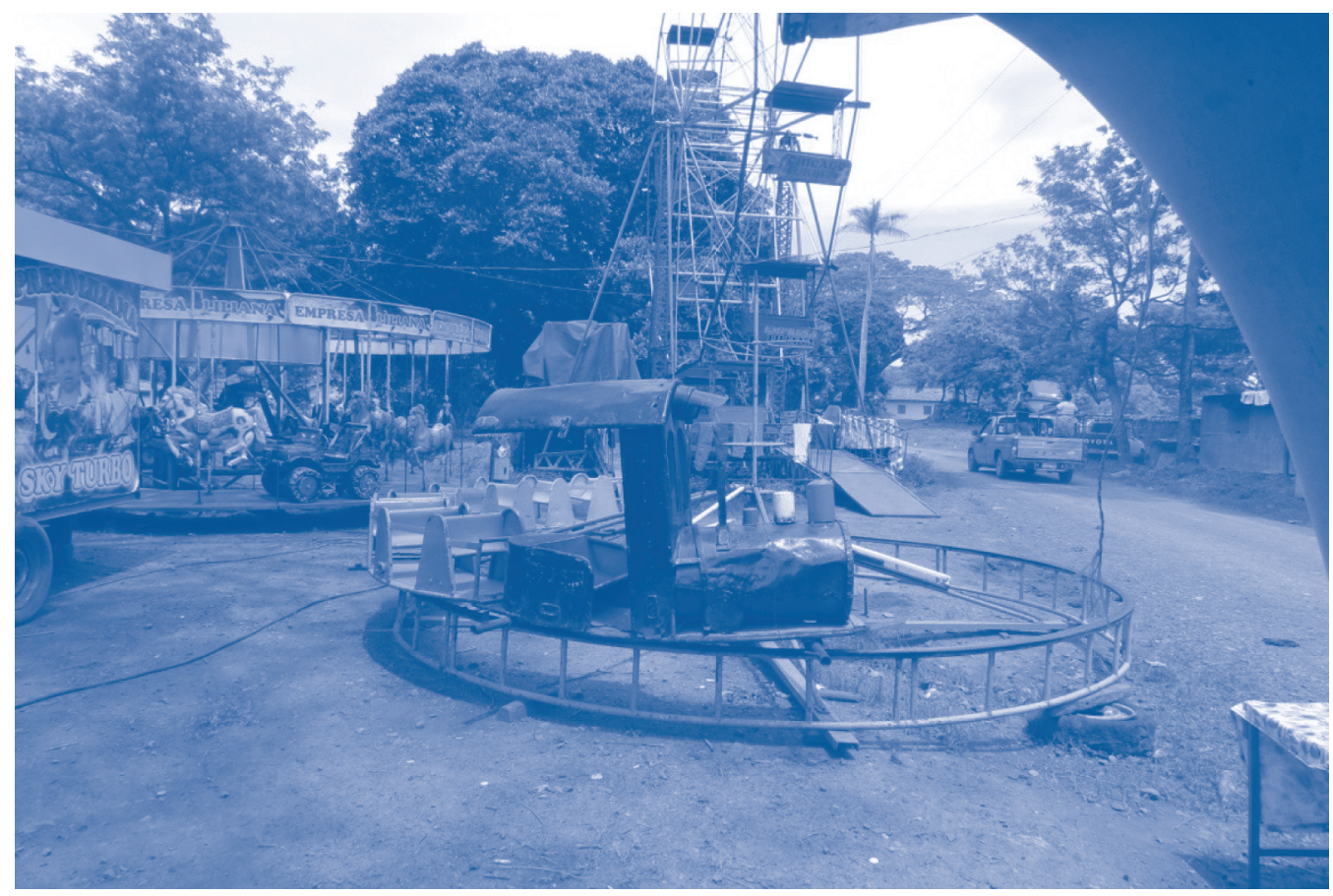

Vista de los juegos mecánicos en los preparativos de la fiesta patronales de san Juan, patrono del caserío San Juan Buenavista, antigua hacienda añilera del mismo nombre. 